\title{
Natural Nanoparticles, Anthropogenic Nanoparticles, Where Is the Frontier?
}

\author{
Gaëtane Lespes ${ }^{1 * t}$, Stéphane Faucher ${ }^{1 \dagger}$ and Vera I. Slaveykova ${ }^{2 * t}$ \\ 1 University of Pau and Pays de l'Adour (E2S/UPPA), Institut des Sciences Analytiques et de Physico-Chimie pour \\ l'Environnement et les Matériaux, UMR UPPA/CNRS, Pau, France, ' Environmental Biogeochemistry and Ecotoxicology, \\ Department F.-A. Forel for Environmental and Aquatic Sciences, School of Earth and Environmental Sciences, Faculty \\ of Science, University of Geneva, Geneva, Switzerland
}

\section{OPEN ACCESS}

Edited by:

Moritz Bigalke,

University of Bern, Switzerland

Reviewed by:

Arturo A. Keller,

University of California, Santa Barbara, United States Michael Hochella, Virginia Tech, United States

*Correspondence: Gaëtane Lespes gaetane.lespes@univ-pau.fr Vera I. Slaveykova

vera.slaveykova@unige.ch

tORCID:

Gaëtane Lespes orcid.org/0000-0002-1752-8923 Stéphane Faucher orcid.org/0000-0001-8887-6055 Vera I. Slaveykova orcid.org/0000-0002-8361-2509

Specialty section:

This article was submitted to Biogeochemical Dynamics,

a section of the journal

Frontiers in Environmental Science

Received: 26 March 2020

Accepted: 12 May 2020

Published: 29 May 2020

Citation:

Lespes G, Faucher S and Slaveykova VI (2020) Natural Nanoparticles, Anthropogenic Nanoparticles, Where Is the Frontier?

Front. Environ. Sci. 8:71. doi: 10.3389/fenvs.2020.00071
Nano-sized particles are important components of the Earth biogeochemical system. However, in the Anthropocene, the human activities disturbed their natural cycle and increased their abundance by (i) affecting their emissions and releases; (ii) altering the environmental processes involving nanoparticles; and (iii) introducing anthropogenic nanoparticles (ANPs). Intentionally or unintentionally released, the occurrence of the anthropogenic particles in the environment is continuously rising. Both natural and anthropogenic nanoparticles are recognized as important carriers for trace elements and organic micropollutants and key modifiers of their transport, speciation, bioavailability, and effects in the environment. Nevertheless, currently they are considered separately, despite the necessity of more integrated, broader, and non-sectorial perspective taking together particles of different origins and various processes likely to generate and involve them. The present paper provides a perspective on the environmental processes involving anthropogenic and natural nanoparticles (NNPs) and discusses the role of human activities in nanoparticle cycling, as well as the necessity to bridge the divide between the NNPs and ANPs. The discussion will be supported by the examples of our own research to ask, if there is still a frontier between NNPs and ANPs?

Keywords: nanoparticle biogeochemical cycle, pollution, nanoparticle sources, fate, toxicity, Anthropocene

\section{INTRODUCTION}

Nano-sized particles, ${ }^{1}$ naturally present in the Earth, move through different compartments (biosphere, lithosphere, atmosphere, and hydrosphere) within global biogeochemical cycle. They play an important, but not fully understood, role in the dynamics of the overall Earth system. However, human activities disturbed the cycle of natural nanoparticles (NNPs) by (i) affecting their emissions and releases; (ii) altering the environmental processes involving nanoparticles; and (iii) introducing anthropogenic nanoparticles (ANPs). Both incidentally released nanoparticles (INPs) ${ }^{2}$

\footnotetext{
${ }^{1}$ Although still a question of debate, nano-sized particles definition used in the present paper involve any object (organic, inorganic, or organometallic) of nanometric size (or sub-micrometric size), which can be in dispersed form in a fluid (Faucher et al., 2019; IUPAC, 2019) and the small dimensions confer them peculiar physical and chemical properties that differ from larger objects made of the same material(s) (Maurice and Hochella, 2008). Natural nanoparticle describes a sub-set of the colloidal phase.

${ }^{2}$ Incidental nanoparticles are produced as a result of any form of direct or indirect anthropogenic activity or process.
} 
and engineered nanoparticles (ENPs) ${ }^{3}$ form the pool of the ANPs. It is estimated that 1000s of $\mathrm{Tg}$ of NNPs, $1-10 \mathrm{Tg}$ of INPs and less than $1 \mathrm{Tg}$ of ENPs from different natural and anthropogenic sources co-exist and move annually between the Earth compartments (Hochella et al., 2019). Despite their small proportion of the total nano-sized particle mass, the amount of ENPs in the environmental compartments continues to increase with ever growing use of nano-enabled materials (Keller and Lazareva, 2014). ENPs were recently considered within the frame of global anthropogenic cycling of elements, concluding that for elements such $\mathrm{Ag}, \mathrm{Al}, \mathrm{Ce}, \mathrm{Co}, \mathrm{Cu}, \mathrm{Fe}, \mathrm{Ni}$, and $\mathrm{Zn}$, ENPs had a minor impact on their cycling, whereas $\mathrm{SiO}_{2}$ ENPs represented $3-25 \%$ of mined Si (Janković and Plata, 2019). However, such integrated Earth system approach has emerged only recently; NNPs and ANPs are thus in most cases considered separately. Only few examples can be found in the literature providing a comprehensive comparison of the behavior of NNPs and ENPs (Baalousha et al., 2011; Wagner et al., 2014; Sigmund et al., 2018). Therefore, broader and integrated approach toward fate and impact of nano-sized particles in the environment would be useful for better understanding Earth systems biogeochemical dynamics. This requires considering nano-sized particles of different origins together with the various processes likely to generate and involve them.

\section{NANOPARTICLE CYCLING IN THE ENVIRONMENT}

Natural nanoparticles are generated in different environmental compartments by various physical, chemical, and biological processes (Figure 1), such as (bio)chemical weathering of minerals, photo-oxidation, redox and precipitation reactions, (bio)mineralization, physical fragmentation, gas-solid nucleation in the atmosphere, etc. (Sharma et al., 2015). ANPs generation is a result of human-related activity or processes (e.g., combustion), due to the life cycle of products containing nanoparticles or accidental releases. Examples of such sources inherent for human activities include: (i) dust generation by various activities; typically mining, tillage, and demolition/construction. Atmospheric transport then constitutes a vector of longdistance transport (Jun et al., 2016); (ii) atmospheric release and nucleation (Lee et al., 2019); (iii) release of treated and untreated waste water (Brar et al., 2010); and (iv) storage in an insufficiently confined area or spreading of sludge from sewage treatment plants (Meier et al., 2016). Natural processes could also be responsible for the generation of the ANPs from different materials. For example, weathering of plastics could result in a formation of micro- and nano-plastics in waters and marine organisms (Ganesh Kumar et al., 2020; Kögel et al., 2020).

Independently on their origin, the nano-sized particles interact with different abiotic and biotic components, via various interconnected processes leading to their transformation in the environmental compartments. Processes such as aggregation,

\footnotetext{
${ }^{3}$ Engineered nanoparticles are purposely designed and produced by humans. Usually defined as particles with a size between 1 and $100 \mathrm{~nm}$ (IUPAC, 2019).
}

sedimentation, biological accumulation, biomagnification, dissolution, chemical and physical alterations, etc., are common for both NNPs and ANPs (Baalousha et al., 2011; Wagner et al., 2014; Sigmund et al., 2018). The nano-sized particles, regardless of their origin, participate in the same bio-physicochemical processes (Figure 1), which ultimate will determine their fate and impacts (Garner et al., 2017, 2018). The fate and behavior of bare ENPs was similar to their natural counterparts with the same composition (Garner and Keller, 2014; Wagner et al., 2014; Sigmund et al., 2018). Human activities also affect these processes by changing the surrounding physical and/or chemical conditions that govern them.

These processes depend on the multiple factors that can be grouped in three main categories intrinsic to: (i) nanosized particles, including particle physicochemical speciation, size, shape, surface functionalization, etc.; (ii) environmental variables, including $\mathrm{pH}$, water hardness, and alkalinity, presence and concentrations of different ligands from natural and anthropogenic origins, which may influence chemical and physicochemical speciation; and (iii) biological systems, including habitat, feeding pattern, etc. Abundant information on the environmental implications of ENPs can be found in recent review papers (Lead et al., 2018; Joonas et al., 2019; Mortimer and Holden, 2019; Kögel et al., 2020; Slaveykova et al., 2020).

It is out of the scope to provide a detailed overview on the fate and impact of the nano-sized materials in the environment. Hence, we make a parallel in some key properties and processes to consider toward bridging the gap between NNPs and ANPs.

\section{TOWARD BRIDGING THE GAP BETWEEN NNPS AND ANPS}

Whatever their origin, nano-sized particles are characterized by a greater fraction of atoms at the surface, which determine their enhanced surface energy and reactivity (Hochella et al., 2019). Purposely-made ENPs have controlled chemical composition, size, and properties. They therefore have less polydisperse character and some properties are enhanced as compared with NNPs. For example, due to their controlled surface structure and smaller sizes $\mathrm{TiO}_{2}$ ENPs have catalytic and redox properties that natural ones do not present (Chin et al., 2011). In addition, the presence of persistent engineered coatings on the ENPs gives them properties which differ from the core material in terms of dissolution, stability and effects. Similarly to NNPs, the surface of ANPs is modified in the environmental and living systems, through the adsorption and desorption of organic and inorganic compounds of natural or anthropogenic origin. Such alterations can affect surface properties of nano-sized particles, hence their interactions with trace elements, organic micropollutants, colloids, surfaces, and biota (Wagner et al., 2014; Wang et al., 2015). Therefore, the pure synthetic identity of ENPs could also be questioned given their interactions with different naturally occurring compounds. The existence of "purely natural" NNPs is a source of interrogation insofar as the whole of the biosphere concerned by the processes of genesis and by materials/compounds qualified as natural are 


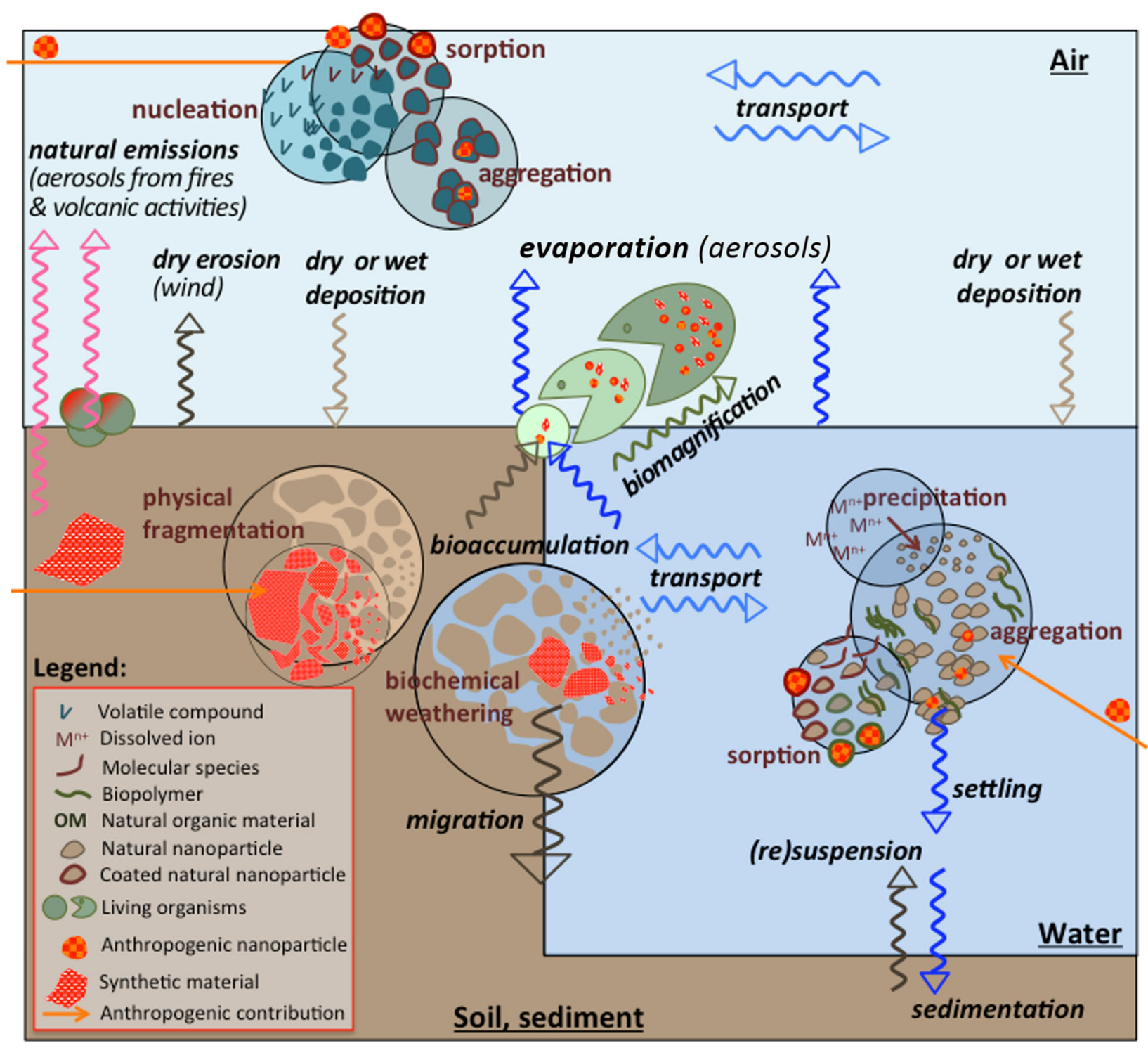

FIGURE 1 | Nano-sized particles in the environmental compartments. Processes governing their distribution among environmental compartments (in italic), their formation, and their transformation (in circles) are highlighted. ANPs (in red) originating from macroscopic or nanomaterials, once released into the environment take part in the same distribution and transformation processes.

possibly affected by human activities. It would therefore be useful to consider that "altered" nano-sized particles involve both anthropogenic and natural components and thus would have more complex environmental fate and impact. Hereafter, we provide shortly two examples considering the interactions of the ANPs with naturally occurred compounds and of the NNPs with inorganic and organic pollutants.

\section{Interaction of ANPs With Naturally Occurring Compounds}

Interaction of ANPs with various naturally occurring compounds (e.g., humic acid, extracellular polymeric substances, peptides) results in a formation of eco-corona and gives them new surface properties (Louie et al., 2016; Pulido-Reyes et al., 2017). This new "environmental identity" has a great influence on their fate by affecting their dissolution, aggregation/agglomeration, stability in the water column (Gigault et al., 2012; Wang et al., 2015; Louie et al., 2016), deposition to mineral surfaces (Louie et al., 2016), attachment to biological surfaces and bioavailability (von Moos et al., 2014; Louie et al., 2016), and toxicity (Ivask et al., 2014; von Moos and Slaveykova, 2014). For example, natural organic matter was shown to reduce the toxicity of metallic nanoparticles to many organisms (Wang et al., 2016).

Similarly, in biological environment, ANPs interact with various biomolecules (e.g., proteins, peptides, DNA, RNA, lipids, etc.) and earn a new "biological identity" determining nanoparticle fate and effects within living organisms. For 
example, the antioxidant enzyme catalase formed a corona around AgNPs, and the released Ag together with AgNPs inhibited its enzymatic activity. However, AgNP-superoxide dismutase complex formation only slightly affected the protein conformation and had no impact on the enzymatic activity or AgNP dissolution (Liu et al., 2020). It is currently accepted that the formed bio-corona represents "what the cell sees" (Walczyk et al., 2010). Hence, it plays a critical role in modulation of the biological reactivity and nano-sized particle induced responses in living organisms, which may be significantly distinct from the expected one exclusively driven by the primary ENPs synthetic identity.

\section{Interaction of NNPs With Inorganic and Organic Pollutants}

Due to their small size and large specific surface area, NNPs play a key role in the transport, speciation, and bioavailability, and thus the ultimate impact of trace elements (Slaveykova and Wilkinson, 2005; Wilkinson and Lead, 2007; El Hadri et al., 2016), and organic micropollutants (Sigmund et al., 2018). NNPs possess a near infinite array of possible compositions and sizes and include principally oxides and oxyhydroxides of iron, manganese, and aluminum and aluminosilicates; humiclike substances, various biopolymers synthesized and released by living organisms involving various proteins, nucleic acids, and polysaccharides (Wilkinson and Lead, 2007; Hartland et al., 2011). Clear size dependence in a preferential binding of trace metals on NNPs was observed (Worms et al., 2010a,b). Following the adsorption of different inorganic and organic contaminants, the NNPs will acquire a new "anthropogenic identity," which will have an important consequence for the pollutant availability and

\section{REFERENCES}

Baalousha, M., Lead, J., Ju-Nam, Y., and Wilderer, P. (2011). Natural colloids and manufactured nanoparticles in aquatic and terrestrial systems. Treat. Water Sci. 3, 89-129. doi: 10.1016/b978-0-444-53199-5.00053-1

Brar, S. K., Verma, M., Tyagi, R. D., and Surampalli, R. Y. (2010). Engineered nanoparticles in wastewater and wastewater sludge - Evidence and impacts. Waste Manag. 30, 504-520. doi: 10.1016/j.wasman.2009.10.012

Chin, S., Park, E., Kim, M., Bae, G.-N., and Jurng, J. (2011). Synthesis and photocatalytic activity of $\mathrm{TiO} 2$ nanoparticles prepared by chemical vapor condensation method with different precursor concentration and residence time. J. Coll. Interf. Sci. 362, 470-476. doi: 10.1016/j.jcis.2011.06.034

El Hadri, H., Lespes, G., Chery, P., and Potin-Gautier, M. (2016). Asymmetric flowfield flow fractionation-multidetection coupling for assessing colloidal copper in drain waters from a bordeaux wine-growing area. Anal. Bioanal. Chem. 406, 1111-1119. doi: 10.1007/s00216-013-7104-x

Faucher, S., Le Coustumer, P., and Lespes, G. (2019). Nanoanalytics: history, concepts, and specificities. Environ. Sci. Pollut. Res. 26, 5267-5281. doi: 10.1007/ s11356-018-1646-6

Ganesh Kumar, A., Anjana, K., Hinduja, M., Sujitha, K., and Dharani, G. (2020). Review on plastic wastes in marine environment - Biodegradation and biotechnological solutions. Mar. Pollut. Bull. 150:110733. doi: 10.1016/j. marpolbul.2019.110733

Garner, K. L., and Keller, A. A. (2014). Emerging patterns for engineered nanomaterials in the environment: a review of fate and toxicity studies. J. Nanopart. Res. 16:2503. doi: 10.1007/s11051-014-2503-2

Garner, K. L., Qin, Y., Cucurachi, S., Suh, S., and Keller, A. A. (2018). Linking exposure and kinetic bioaccumulation models for metallic engineered biological outcomes. For example, in the aquatic environment, NNPs reduce the bioavailability of the trace metals to various organisms, including bacteria, fungus, phytoplankton, daphnia, and fish, in direct proportion to the free metal ion concentrations (Slaveykova and Wilkinson, 2005). NNPs could therefore play the role of Trojan horses for their associated pollutants and increase the trace metals bioavailability to filter feeders (e.g., clams, mussels, and oysters) (Luoma and Rainbow, 2005). Similarly, the adsorption of metallic pollutants on ENPs could result in their surface modification, which could change their properties and the way they interact with biota (Naasz et al., 2018; Li et al., 2020).

Overall, despite the existing differences between NNPs and ANPs, similar properties and processes control their fate and effects in the environment. Therefore, processoriented knowledge has a potential to lead to sound progress in the understanding the nano-sized particles dynamics in the multifaceted Earth (sub-) systems, and feedbacks with human activity.

\section{DATA AVAILABILITY STATEMENT}

Publicly available datasets were analyzed in this study. Requests to access the data can be directed to gaetane.lespes@univ-pau.fr.

\section{AUTHOR CONTRIBUTIONS}

GL and VS took part in conceptualization, manuscript writing, and editing. SF drew the figure and took part in the manuscript writing. All authors read and agreed to the published version of the manuscript.

nanomaterials in freshwater ecosystems. ACS Sustain. Chem. Eng. 6, 1268412694. doi: 10.1021/acssuschemeng.8b01691

Garner, K. L., Suh, S., and Keller, A. A. (2017). Assessing the risk of engineered nanomaterials in the environment: development and application of the nanofate model. Environ. Sci. Technol. 51, 5541-5551. doi: 10.1021/acs.est. $6 \mathrm{~b} 05279$

Gigault, J., Grassl, B., and Lespes, G. (2012). Size characterization of the associations between carbon nanotubes and humic acids in aqueous media by asymmetrical flow field-flow fractionation combined with multi-angle light scattering. Chemosphere 86, 177-182. doi: 10.1016/j.chemosphere.2011.10.009

Hartland, A., Fairchild, I. J., Lead, J. R., Zhang, H., and Baalousha, M. (2011). Size, speciation and lability of NOM-metal complexes in hyperalkaline cave dripwater. Geochim. Cosmochim. Acta 75, 7533-7551. doi: 10.1016/j.gca.2011. 09.030

Hochella, M. F., Mogk, D. W., Ranville, J., Allen, I. C., Luther, G. W., Marr, L. C., et al. (2019). Natural, incidental, and engineered nanomaterials and their impacts on the Earth system. Science 363:eaau8299. doi: 10.1126/science. aau 8299

IUPAC, (2019). International Union of Pure and Applied Chemistry - Compendium of Chemical Terminology, Gold Book. Research Triangle Park, CA: IUPAC.

Ivask, A., Juganson, K., Bondarenko, O., Mortimer, M., Aruoja, V., Kasemets, K., et al. (2014). Mechanisms of toxic action of $\mathrm{Ag}, \mathrm{ZnO}$ and $\mathrm{CuO}$ nanoparticles to selected ecotoxicological test organisms and mammalian cells in vitro: a comparative review. Nanotoxicology 8, 57-71. doi: 10.3109/17435390.2013. 855831

Janković, N. Z., and Plata, D. L. (2019). Engineered nanomaterials in the context of global element cycles. Environ. Sci. Nano 6, 2697-2711. doi: 10.1039/ C9EN00322C 
Joonas, E., Aruoja, V., Olli, K., and Kahru, A. (2019). Environmental safety data on $\mathrm{CuO}$ and $\mathrm{TiO} 2$ nanoparticles for multiple algal species in natural water: filling the data gaps for risk assessment. Sci. Total Environ. 647, 973-980. doi: 10.1016/j.scitotenv.2018.07.446

Jun, Y.-S., Kim, D., and Neil, C. W. (2016). Heterogeneous nucleation and growth of nanoparticles at environmental interfaces. Acc. Chem. Res. 49, 1681-1690. doi: $10.1021 /$ acs.accounts.6b00208

Keller, A. A., and Lazareva, A. (2014). Predicted releases of engineered nanomaterials: from global to regional to local. Environ. Sci. Technol. Lett. 1, 65-70. doi: 10.1021/ez400106t

Kögel, T., Bjorøy, Ø, Toto, B., Bienfait, A. M., and Sanden, M. (2020). Microand nanoplastic toxicity on aquatic life: determining factors. Sci. Total Environ. 709:136050. doi: 10.1016/j.scitotenv.2019.136050

Lead, J. R., Batley, G. E., Alvarez, P. J. J., Croteau, M. N., Handy, R. D., McLaughlin, M. J., et al. (2018). Nanomaterials in the environment: behavior, fate, bioavailability, and effectsAn updated review. Environ. Toxicol. Chem. 37, 2029-2063. doi: 10.1002/etc.4147

Lee, S.-H., Gordon, H., Yu, H., Lehtipalo, K., Haley, R., Li, Y., et al. (2019). New particle formation in the atmosphere: from molecular clusters to global climate. J. Geophys. Res. Atmos. 124, 7098-7146. doi: 10.1029/2018jd029356

Li, M., Liu, W., and Slaveykova, V. I. (2020). Effects of mixtures of engineered nanoparticles and metallic pollutants on aquatic organisms. Environments 7:27. doi: 10.3390/environments7040027

Liu, W., Worms, I., and Slaveykova, V. I. (2020). Interaction of silver nanoparticles with antioxidant enzymes. Environ. Sci. Nano doi: 10.1039/C9EN01284B

Louie, S. M., Tilton, R. D., and Lowry, G. V. (2016). Critical review: impacts of macromolecular coatings on critical physicochemical processes controlling environmental fate of nanomaterials. Environ. Sci. Nano 3, 283-310. doi: 10. 1039/C5EN00104H

Luoma, S. N., and Rainbow, P. S. (2005). Why is metal bioaccumulation so variable? Biodynamics as a unifying concept. Environ. Sci. Technol. 39, 1921-1931. doi: 10.1021/es048947e

Maurice, P. A., and Hochella, M. F. (2008). Chapter 5 nanoscale particles and processes: a new dimension in soil science. Adv. Agron. 100, 123-153. doi: 10.1016/s0065-2113(08)00605-6

Meier, C., Voegelin, A., Pradas del Real, A., Sarret, G., Mueller, C. R., and Kaegi, R. (2016). Transformation of silver nanoparticles in sewage sludge during incineration. Environ. Sci. Technol. 50, 3503-3510. doi: 10.1021/acs.est.5b04804

Mortimer, M., and Holden, P. A. (2019). "Chapter 3 - fate of engineered nanomaterials in natural environments and impacts on ecosystems," in Exposure to Engineered Nanomaterials in the Environment, eds N. Marmiroli, J. C. White, and J. Song (Amsterdam: Elsevier), 61-103. doi: 10.1016/b978-012-814835-8.00003-0

Naasz, S., Altenburger, R., and Kühnel, D. (2018). Environmental mixtures of nanomaterials and chemicals: The Trojan-horse phenomenon and its relevance for ecotoxicity. Sci. Tot. Environ. 635, 1170-1181. doi: 10.1016/j.scitotenv.2018. 04.180

Pulido-Reyes, G., Leganes, F., Fernández-Piñas, F., and Rosal, R. (2017). Bionano interface and environment: a critical review. Environ. Toxicol. Chem. 36, 3181-3193. doi: $10.1002 /$ etc. 3924

Sharma, V. K., Filip, J., Zboril, R., and Varma, R. S. (2015). Natural inorganic nanoparticles - formation, fate, and toxicity in the environment. Chem. Soc. Rev. 44, 8410-8423. doi: 10.1039/C5CS00236B
Sigmund, G., Jiang, C., Hofmann, T., and Chen, W. (2018). Environmental transformation of natural and engineered carbon nanoparticles and implications for the fate of organic contaminants. Environ. Sci. Nano 5, 2500-2518. doi: 10.1039/C8EN00676H

Slaveykova, V. I., Li, M., Worms, I. A., and Liu, W. (2020). When environmental chemistry meets ecotoxicology: bioavailability of inorganic nanoparticles to phytoplankton. CHIMIA 74, 115-121. doi: 10.2533/chimia.20 20.115

Slaveykova, V. I., and Wilkinson, K. J. (2005). Predicting the bioavailability of metals and metal complexes: critical review of the biotic ligand model. Environ. Chem. 2, 9-24. doi: 10.1071/en04076

von Moos, N., Bowen, P., and Slaveykova, V. I. (2014). Bioavailability of inorganic nanoparticles to planktonic bacteria and aquatic microalgae in freshwater. Environ. Sci. Nano 1, 214-232. doi: 10.1039/c3en00054k

von Moos, N., and Slaveykova, V. I. (2014). Oxidative stress induced by inorganic nanoparticles in bacteria and aquatic microalgae - state of the art and knowledge gaps. Nanotoxicology 8, 605-630. doi: 10.3109/17435390.2013. 809810

Wagner, S., Gondikas, A., Neubauer, E., Hofmann, T., and von der Kammer, F. (2014). Spot the difference: engineered and natural nanoparticles in the environment-release, behavior, and fate. Angewa. Chem. Intern. Edn. 53, 12398-12419. doi: 10.1002/anie.201405050

Walczyk, D., Bombelli, F. B., Monopoli, M. P., Lynch, I., and Dawson, K. A. (2010). What the cell "sees" in bionanoscience. J. Am. Chem. Soc. 132, 5761-5768. doi: $10.1021 /$ ja910675v

Wang, H., Adeleye, A. S., Huang, Y., Li, F., and Keller, A. A. (2015). Heteroaggregation of nanoparticles with biocolloids and geocolloids. Adv. Coll. Interf. Sci. 226, 24-36. doi: 10.1016/j.cis.2015.07.002

Wang, Z., Zhang, L., Zhao, J., and Xing, B. (2016). Environmental processes and toxicity of metallic nanoparticles in aquatic systems as affected by natural organic matter. Environ. Sci. Nano 3, 240-255. doi: 10.1039/C5EN0 0230C

Wilkinson, K. J., and Lead, J. R. (2007). Environmental Colloids and Particles. Behaviour, Separation and Characterisation. Chichester: John Wiley Sons, Ltd.

Worms, I. A. M., Szigeti, Z. A. G., Dubascoux, S., Lespes, G., Traber, J., Sigg, L., et al. (2010a). Colloidal organic matter from wastewater treatment plant effluents: characterization and role in metal distribution. Water Res. 44, 340-350. doi: 10.1016/j.watres.2009.09.037

Worms, I. A. M., Traber, J., Kistler, D., Sigg, L., and Slaveykova, V. I. (2010b). Uptake of $\mathrm{Cd}(\mathrm{II})$ and $\mathrm{Pb}(\mathrm{II})$ by microalgae in presence of colloidal organic matter from wastewater treatment plant effluents. Environ. Pollut. 158, 369 374. doi: 10.1016/j.envpol.2009.09.007

Conflict of Interest: The authors declare that the research was conducted in the absence of any commercial or financial relationships that could be construed as a potential conflict of interest.

Copyright (c) 2020 Lespes, Faucher and Slaveykova. This is an open-access article distributed under the terms of the Creative Commons Attribution License (CC BY). The use, distribution or reproduction in other forums is permitted, provided the original author(s) and the copyright owner(s) are credited and that the original publication in this journal is cited, in accordance with accepted academic practice. No use, distribution or reproduction is permitted which does not comply with these terms. 